\title{
Integration of early identification and brief intervention in frontline health services: the case of Quebec
}

\author{
Marianne Saint-Jacques ${ }^{1 *}$, Thomas G Brown ${ }^{2}$, Sarah Filion-Bilodeau ${ }^{3}$, John Topp ${ }^{4}$, David Ross ${ }^{4}$, Lucie Legault ${ }^{5}$ \\ From International Network on Brief Interventions for Alcohol Problems (INEBRIA) Meeting 2011 \\ Boston, MA, USA. 21-23 September 2011
}

In 2006, the Quebec provincial government committed itself to developing capacity for evidence-based alcohol and other drug screening and brief intervention (SBI) in frontline health-service delivery settings. Two studies were conducted prior to province-wide deployment to inform decision makers as to possible implementation challenges. Study 1 evaluated the efficacy of implementing a model of SBI, adapted from the World Health Organization, in three frontline public health services. Sixty-two clinicians were trained in systematic detection of substance use and brief motivational intervention. Chart review of new admissions $(\mathrm{N}=453)$ prior and following training assessed clinician conformity to SBI guidelines. Forty percent of patients endorsed at least one item on the four-question CAGE-AID (Cut Down, Annoyed, Guilty, Eye Opener screen Adapted to Include Drugs). Systematic screening among new admissions peaked at $70 \%$ and decreased to pre-training levels seven months after training. However, more than half of all new patients were assessed with validated questionnaires rather than informal questioning. Implementation of motivational interviewing techniques led to modest changes in clinician interventions. A second qualitative study was conducted to document possible organizational barriers to SBI implementation. Interviews were conducted with 24 clinicians and program administrators from frontline services of the six main health regions of Quebec province. Choice of vocabulary used in public policy documents and program material and sequence of delivery of services created confusion among clinicians as to what constituted alcohol and other drug SBI. Many resources developed for other SBI health programs in these frontline services seemed to be transferable

Department of Medicine and Health Sciences, University of Sherbrooke, Longueuil, Quebec, Canada

Full list of author information is available at the end of the article to alcohol and drug SBI. Lessons learned were as follows: complexity in the SBI program is inversely related to the subsequent integrity of program deployment; clarity as to what constitutes SBI is paramount; and integration of parallel competencies/related programs could facilitate deployment of alcohol and other drug SBI.

\section{Author details}

'Department of Medicine and Health Sciences, University of Sherbrooke, Longueuil, Quebec, Canada. ${ }^{2}$ Addiction Research Center, McGill University, Montreal, Quebec, Canada. ${ }^{3}$ Douglas Mental Health University Institute, McGill University, Montreal, Quebec, Canada. ${ }^{4}$ Addiction Services, Pavillon Foster Addiction Treatment Center, St. Philippe de Laprairie, Canada. ${ }^{5}$ Addiction Research Program, Douglas Mental Health University Institute, Montreal, Quebec, Canada.

Published: 9 October 2012

doi:10.1186/1940-0640-7-S1-A74

Cite this article as: Saint-Jacques et al: Integration of early identification and brief intervention in frontline health services: the case of Quebec. Addiction Science \& Clinical Practice 2012 7(Suppl 1):A74.

Submit your next manuscript to BioMed Central and take full advantage of:

- Convenient online submission

- Thorough peer review

- No space constraints or color figure charges

- Immediate publication on acceptance

- Inclusion in PubMed, CAS, Scopus and Google Scholar

- Research which is freely available for redistribution
C Biomed Central

(c) 2012 Saint-Jacques et al; licensee BioMed Central Ltd. This is an Open Access article distributed under the terms of the Creative Commons Attribution License (http://creativecommons.org/licenses/by/2.0), which permits unrestricted use, distribution, and reproduction in any medium, provided the original work is properly cited. 